(C) 2020, The Authors. Published by Elsevier Inc. and Fass Inc. on behalf of the American Dairy Science Association ${ }^{\circledR}$. This is an open access article under the CC BY-NC-ND license (http://creativecommons.org/licenses/by-nc-nd/4.0/).

\title{
Prenatal exposure to different diets influences programming of glucose and insulin metabolism in dairy ewes
}

\author{
M. F. Lunesu, ${ }^{1} \odot$ A. Ledda, ${ }^{1}$ F. Correddu, ${ }^{1} \odot$ F. Fancello, ${ }^{1} \odot$ A. Marzano, ${ }^{1}$ F. Mossa, ${ }^{2} \odot$ A. Nudda, ${ }^{1} \odot$ A. Cannas, ${ }^{1}$ \\ and A. S. Atzori ${ }^{1 *}$ (B) \\ ${ }^{1}$ Dipartimento di Agraria, University of Sassari, 07100 Sassari, Italy \\ ${ }^{2}$ Dipartimento di Medicina Veterinaria, University of Sassari, 07100 Sassari, Italy
}

\begin{abstract}
Nutrition in fetal and postnatal life can influence the development of several biological systems, with permanent effects in adult life. The aim of this work was to investigate in dairy sheep whether diets rich in starch or fiber during intrauterine life (75 d before lambing) and postnatal life (from weaning to first pregnancy; growth phase) program glucose and insulin metabolism in the female offspring during their first pregnancy. Starting from intrauterine life, 20 nulliparous Sarda ewes were exposed to 4 dietary regimens $(\mathrm{n}=5$ per group) based on different dietary carbohydrates during their intrauterine life and their subsequent growth phase: (1) the fiber (FI) diet during both intrauterine and growth life, (2) the starch (ST) diet during both intrauterine and growth life, (3) the FI diet in intrauterine life followed by the ST diet in the growth phase, and (4) the ST diet in intrauterine life followed by the FI diet in the growth phase. After the end of the growth phase, all growing ewes were fed the same diet and naturally mated. When ewes were pregnant, on average at $124 \pm 2 \mathrm{~d}$ of gestation they were challenged with an intravenous glucose tolerance test, and peripheral concentrations of glucose and insulin were determined. Basal insulin concentrations were higher in ewes exposed to the ST diet $(0.97$ $\mu \mathrm{g} / \mathrm{L})$ than in ewes exposed to the FI diet $(0.52 \mu \mathrm{g} / \mathrm{L})$ in intrauterine life. After glucose infusion, glucose and insulin concentrations were not affected by intrauterine diet. Insulin resistance, determined by the homeostasis model assessment, was affected by the intrauterine $x$ growth phases interaction. Insulin sensitivity, assessed by the quantitative insulin check index, was lower in ewes exposed to the ST diet than in those exposed to the FI diet in intrauterine life $(\mathrm{ST}=0.28 ; \mathrm{FI}=0.30)$. Diet in growth life had no effect on glucose and insulin
\end{abstract}

Received February 10, 2020.

Accepted May 15, 2020.

*Corresponding author: asatzori@uniss.it metabolism. In conclusion, starchy diets offered during intrauterine life but not during postnatal life increased basal insulin level and lowered insulin sensitivity during the first pregnancy. Nutritional strategies of metabolic programming should consider that exposure to starchy diets in late fetal life might favor the programming of dietary nutrient partitioning toward organs with high requirements, such as the gravid uterus or the mammary gland.

Key words: fetal programming, sheep, fiber, starch

\section{INTRODUCTION}

The early life environment plays an important role in the long-term health of individuals, specifically acting on development, physiological regulation, and incidence of disease in adult mammals (Barker, 2007; Cottrell and Ozanne, 2008). Evidence from both animal and human studies indicates that environmental and nutritional stimuli occurring before birth can permanently program physiological systems due to the high plasticity of the developing fetus (Cottrell and Ozanne, 2008; Symonds et al., 2009; Paliy et al., 2014). Specifically, the exposure to imbalanced diets (e.g., undernutrition, overnutrition, excess dietary fat) in fetal life and postnatal life seems to be associated with higher risk of developing insulin resistance, low insulin sensitivity, lower glucose tolerance, and altered lipid and glucose metabolism in humans (Ravelli et al., 1998), monogastric animals (George et al., 2009; Coverdale et al., 2015), and ruminants (Kenyon and Blair, 2014; Parlee and MacDougald, 2014; Khanal and Nielsen, 2017).

In ruminants, the development of low insulin sensitivity decreases the biological response to insulin in sensitive tissues, such as the muscle and isolated adipocytes (Kahn, 1978; Baumgard et al., 2017). Low insulin sensitivity and other signaling mechanisms not clearly defined (McFadden and Rico, 2019) allow constant nutrient partitioning toward the fetus or the mammary gland (Bauman and Currie, 1980; Aschenbach et al., 
2010). Thus, impaired insulin metabolism induced by pre- and postnatal nutrition levels could have a central role in peripheral nutrient uptake, directly affecting nutrient partitioning and production performance in adulthood (Symonds et al., 2009; Kenyon and Blair, 2014; Khanal and Nielsen, 2017). Among ruminants, the sheep model has been used to study effects of maternal nutrition during the periconceptional period (Todd et al., 2009; Long et al., 2010), early and mid gestation (Ford et al., 2007), or late fetal life (Husted et al., 2008) on offspring performance and glucose metabolism (Khanal and Nielsen, 2017). However, all of these studies focused on nutritional level or daily energy balance of the mothers rather than the dietary nutritional components. Indeed, little information is available on the effects of dietary carbohydrates offered in pregnancy on the development and modulation of glucose metabolism. Mossa et al. (2018) showed that maternal diets rich in starch can positively affect reproductive development of male lambs. Furthermore, previous studies in lactating dairy sheep demonstrated that carbohydrate sources (high digestible fiber vs. starch) might influence energy partitioning during mid lactation (Bovera et al., 2004; Cannas et al., 2013), favoring milk synthesis and opposing body fat deposition (Lunesu, 2016; Lunesu et al., 2017). Conversely, goats (Lunesu, 2016) and dairy cows (Ipharraguerre et al., 2002) showed a lower sensitivity to starchy diets in mid lactation, probably due to the effects of animal breeding on milk synthesis drivers (Peel and Bauman, 1987; Accorsi et al., 2005; Pulina et al., 2007). In addition, sheep seem to be more prone than dairy cattle to use acetate as an energy source to spare glucose for the mammary gland and the uterus (Pethick and Lindsay, 1982; Cannas et al., 2002). Thus, the peculiarity of sheep suggests exploring in this species the peripheral sensitivity induced by the response to different dietary carbohydrates in intrauterine and postnatal life.

The intravenous glucose tolerance test (IVGTT) is frequently used to assess insulin sensitivity because it reflects total body glucose metabolism and insulin secretion after the injection of an intravenous glucose bolus (De Koster and Opsomer, 2013; De Koster et al., 2017). In this study, we tested the hypothesis that different dietary carbohydrates during fetal life and the growth phase in female lambs may affect glucose metabolism during their first gestation. The specific objective of this study was to expose dairy ewes to diets rich in starch or high digestible fiber during both intrauterine life and postnatal life (from weaning to first lambing) and to test the potential effects on their glucose and insulin metabolism in late gestation.

\section{MATERIALS AND METHODS}

\section{Experimental Groups and Animal Procedures}

The experiment was conducted on a commercial farm located in northwest Sardinia (Sassari, Italy; $\left.40^{\circ} 48^{\prime} 41.4^{\prime \prime} \mathrm{N}, 8^{\circ} 17^{\prime} 50.7^{\prime \prime} \mathrm{E}\right)$. All procedures involving animals were fully in compliance with Directive 2010/63/EU of the European Parliament (2010) and Italian regulations (DPR 27/1/1992, Animal Protection Regulations of Italy) on animal welfare and experimentation.

Twenty nulliparous Sarda ewes were selected from a larger group of sheep to be challenged with an IVGTT at $124 \pm 2 \mathrm{~d}$ of their first gestation $(23 \pm 2 \mathrm{~d}$ before lambing; mean $\pm \mathrm{SD}$ ). Ewes were selected among those pregnant with a single fetus, having homogeneous BCS (mean $\pm \mathrm{SD}, 2.95 \pm 0.06$ ) and $\mathrm{BW}$ (mean $\pm \mathrm{SD}, 49.15$ $\pm 0.66 \mathrm{~kg}$ ), and in respect to their nutritional history during their late fetal life (intrauterine phase) and growth phase (from $15 \mathrm{~d}$ after birth to their first gestation). The experimental design is described in Figure 1.

Nutritional history during intrauterine life was associated with the diet of their mothers. Diets and animal procedures of the dams were previously described in Mossa et al. (2018). Briefly, dams were naturally mated and pregnancy was diagnosed via transabdominal ultrasonography (MyLabOneVet, Esaote, Genoa, Italy) approximately $25 \mathrm{~d}$ after the introduction of rams in the flock. Pregnant dams were fed the assigned diet (starch, ST, or fiber, FI) 3 times per day $(0930,1530$, and $1930 \mathrm{~h}$ ) for approximately the last $75 \mathrm{~d}$ of pregnancy. Experimental diets were defined as more glucogenic or lipogenic based on their carbohydrate source (van Knegsel et al., 2007). The ST diet contained corn and barley starch, a glucogenic substrate, because its fermentation produces propionate at the rumen level, which in turn is converted into glucose in the liver. In contrast, the FI diet was rich in high digestible insoluble fiber (NDF) and soluble fiber (pectins) from soyhulls. These can be considered lipogenic substrates because their fermentation produces mainly acetate, a precursor of body and milk fatty acids.

The mean $( \pm \mathrm{SD}) \mathrm{BW}$ and BCS of the dams were $48.4 \pm 1.0 \mathrm{~kg}$ of $\mathrm{BW}$ and $2.74 \pm 0.13$, respectively, before the start of the different dietary regimens and $58.6 \pm 1.4 \mathrm{~kg}$ of $\mathrm{BW}$ and $2.67 \pm 0.16$, respectively, at parturition. There were no significant differences among ST and FI dams $(P>0.05)$.

Lamb weight at birth was also similar among groups $(3.53 \pm 0.38 \mathrm{~kg} ; P>0.10)$. After birth, nutritional history was associated with the growth phase, which 


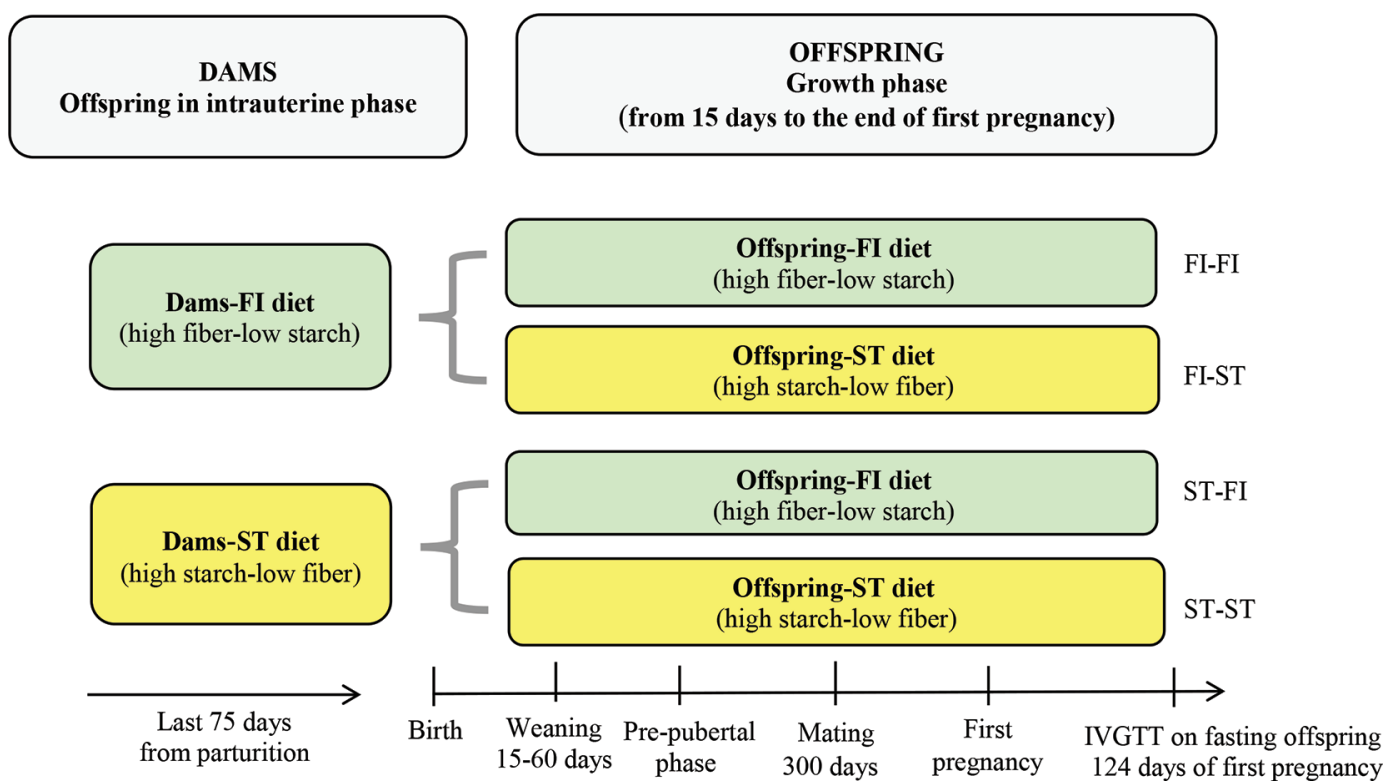

Figure 1. Graphical representation of the experimental design adopted for intravenous glucose tolerance test (IVGTT) during the first pregnancy of the offspring. Ewes were exposed to diets based on different prevalent dietary carbohydrates (fiber, FI, or starch, ST) during the last $75 \mathrm{~d}$ of their intrauterine life and from $15 \mathrm{~d}$ after birth until their first gestation (growth period), resulting in 4 dietary regimens until the IVGTT ( $\mathrm{n}=5$ per group): FI-FI = FI diet during both intrauterine and growth life; FI-ST = FI diet in intrauterine life followed by the ST diet in the growth phase; ST-FI = ST diet in intrauterine life followed by the FI diet in the growth phase; ST-ST = ST diet during both intrauterine and growth life.

lasted 8 mo. Specifically, lambs suckled milk from their mothers until they were $60 \mathrm{~d}$ old and had access to the commercial concentrate used in the growth diets from when they were $15 \mathrm{~d}$ old. After lambing, all of the mothers were fed a diet that included a mix of ST and FI diets. From 15 d after birth to the end of their first gestation, female lambs from the 2 groups of mothers were assigned to 2 dietary groups (ST or FI diets). The assigned dietary concentrate was offered twice a day $(0800$ and $1900 \mathrm{~h})$ in individual headlocks. These female lambs were naturally mated at approximately $300 \mathrm{~d}$ of age, and pregnancy was diagnosed via transabdominal ultrasonography (MyLabOneVet, Esaote) approximately $25 \mathrm{~d}$ after the introduction of rams in the flock. Growth rate from birth to conception was equal to $0.106 \pm 0.008 \mathrm{~kg} / \mathrm{d}$, and there were no significant differences among the 4 groups $(P>0.10)$.

On the day of the IVGTT, the 20 nulliparous offspring belonged to 4 experimental treatments ( $\mathrm{n}=$ 5 per group), which corresponded to 4 the dietary regimens, as follows: (1) the FI diet during both the intrauterine and growth phases (FI-FI), (2) the ST diet during both the intrauterine and growth phases (ST-ST), (3) the FI diet in intrauterine life followed by the ST diet in the growth phase (FI-ST), and (4) the ST diet in intrauterine life followed by the FI diet in the growth phase (ST-FI).

\section{Dietary Regimens}

During the experimental phases, animals were fed a diet consisting of mixed hay (clover and ryegrass) and pelleted experimental concentrates, with a forage: concentrate ratio of $45: 55 \%$ and 40:60\% (DM basis) for the intrauterine and growth phases, respectively. Such concentrates were characterized by different carbohydrate sources; the concentrate used in the ST diet was glucogenic, being rich in starch from corn and barley meals, whereas the concentrate used in the FI diet was lipogenic, with low starch and high content of fiber from soyhulls. The 2 experimental diets were iso-proteic within periods, whereas between periods CP was varied to meet protein requirements of the physiological stages. The CP was lower (about 13\% CP) in intrauterine life and higher (16-17\% CP on average) in the growth phase (Table 1). The offered amount in each phase and the ration balancing were calculated using the Small Ruminant Nutrition System (Tedeschi et al., 2010).

\section{IVGTT}

To study the long-term effect of exposure to different dietary carbohydrates during fetal and growth life on sheep glucose metabolism, the 20 offspring ( $\mathrm{n}=$ 
Table 1. Chemical composition (\% of DM unless noted) of the starchand fiber-based diets supplied during intrauterine and postnatal life (growth period)

\begin{tabular}{|c|c|c|c|c|}
\hline \multirow[b]{2}{*}{ Item } & \multicolumn{2}{|c|}{ Intrauterine phase } & \multicolumn{2}{|c|}{ Growth phase } \\
\hline & Fiber & Starch & Fiber & Starch \\
\hline DM, \% as fed & 88.0 & 88.6 & 88.0 & 88.0 \\
\hline $\mathrm{CP}$ & 14.8 & 14.6 & 15.5 & 16.0 \\
\hline Ash & 10.7 & 9.8 & 8.3 & 7.5 \\
\hline Ether extract & 2.3 & 2.1 & 2.2 & 2.0 \\
\hline NDF & 46.5 & 37.0 & 50.5 & 39.5 \\
\hline $\mathrm{ADF}$ & 37.8 & 25.9 & 37.3 & 27.2 \\
\hline ADL & 2.7 & 2.4 & 2.6 & 2.3 \\
\hline $\mathrm{NFC}^{1}$ & 31.7 & 42.4 & 29.5 & 40.9 \\
\hline Starch & 10.7 & 26.7 & 9.8 & 25.5 \\
\hline
\end{tabular}

${ }^{1}$ Calculated as NFC $=100-\mathrm{CP}-$ ash $-\mathrm{NDF}-$ ether extract.

5 per dietary treatment) were challenged during their first gestation with an IVGTT, partially modifying the procedure described by Morgante et al. (2012). The offspring were deprived of feed $10 \mathrm{~h}$ before the start and during the test. On the morning of the test, sterile catheters were fitted in both jugular veins of each ewe (14 G-cannula, Delta Med, Viadana, Italy). Glucose (dextrose) at $0.5 \mathrm{~g} / \mathrm{kg}$ of BW as a sterile, nonpyrogenic $50 \%$ (wt/vol) solution (in $0.9 \% \mathrm{NaCl}$ ) was infused via a jugular vein catheter. Blood was sampled from the opposite jugular vein 15 min before glucose infusion $(-15)$ and $5,10,15,30,45,90$, and $180 \mathrm{~min}$ after glucose infusion. Blood samples were collected in evacuated tubes with lithium heparin $(9 \mathrm{~mL}$; Venosafe VF-109SHL Lithium Heparin, Terumo Europe NV, Leuven, Belgium) for plasma insulin determination and glucose-NaF/NH (4 mL; Vacucheck, Nuova Aptaca Srl, Canelli, Italy) for plasma glucose determination. All blood samples were immediately centrifuged for 10 min at $1,500 \times g$ at $4^{\circ} \mathrm{C}$, and plasma was immediately frozen and stored at $-80^{\circ} \mathrm{C}$ until analysis.

\section{Hormonal Analyses}

Plasma glucose concentrations were determined using a glucose oxidase-peroxidase method (Shenzen Mindray Bio-Medical Electronics Co., Shenzen, China). Plasma insulin concentrations were determined using an ovinespecific commercial ELISA kit (Ovine Insulin ELISA, Mercodia AB, Uppsala, Sweden) based on the direct sandwich technique, in which 2 monoclonal antibodies are directed against separate antigenic determinants on the insulin molecule. For insulin (sensitivity $=0.025$ $\mu \mathrm{g} / \mathrm{L}$ ), the intra- and interassay coefficients of variation were 3.7 and $6.5 \%$, respectively.

For glucose, the area under the curve $\left(\mathbf{A} \mathbf{U} \mathbf{C}_{\text {glucose; }}\right.$ $\mathrm{mg} / \mathrm{dL} \times \min )$ was calculated using a trapezoidal summation method (linear and transformed logarith- mically). The glucose fractional turnover rate $(\mathbf{k})$ was calculated as glucose $\mathrm{k}(\% / \mathrm{min})=100 \times\{[\ln ($ glucose $\mathrm{T} 15)-\ln ($ glucose $\mathrm{T} 45)] /(\mathrm{T} 45-\mathrm{T} 15)\}$, where $\mathrm{T} 15=$ time at +15 min and $\mathrm{T} 45=$ time at $+45 \mathrm{~min}$, whereas the glucose half time $(\mathbf{T} \mathbf{1} / \mathbf{2}$; the time required for glucose concentration to decrease by half) was calculated as glucose $\mathrm{T} 1 / 2(\mathrm{~min})=100 \times(0.693 / \mathrm{k})$ in accordance with Zachut et al. (2013).

The insulin response was determined by AUC $\left(\mathbf{A U C}_{\text {insulin }} ; \mu \mathrm{g} / \mathrm{L} \times \mathrm{min}\right.$; linear and transformed logarithmically), insulin peak, and insulin increment (the difference between insulin peak and basal insulin) in accordance with Zachut et al. (2013). The insulin resistance was estimated through a homeostasis model assessment (HOMA), calculated as HOMA $=[$ fasting insulin $(\mu \mathrm{IU} / \mathrm{mL}) \times$ fasting glucose $(\mathrm{mmol} / \mathrm{L})] / 22.5$ in accordance with Matthews et al. (1985), whereas the insulin sensitivity was estimated through a quantitative insulin check index (QUICKI), calculated as QUICKI $=1 /[\log$ (fasting glucose, $\mathrm{mg} / \mathrm{dL})+\log ($ fasting insulin, $\mu \mathrm{U} / \mathrm{mL})]$ in accordance with Katz et al. (2000).

\section{Chemical Analyses}

Feed samples were analyzed for DM (after drying at $105^{\circ} \mathrm{C}$ for $24 \mathrm{~h}$ ), for NDF, ADF, and ADL (using Ankom filter bag equipment and including thermostable amylases; Ankom Technology Corp., Fairport, NY; Van Soest et al.,1991), for CP (Kjeldahl method; AOAC International, 2000; method 988.05), for ash (AOAC International, 2000; method 942.05), and for ether extract (EE; AOAC International, 2005; method 920.39). Starch was measured by polarimetry (Polax 2L, Atago, Tokyo, Japan) according to European Commission (1999). The NFC was calculated according to Weiss (1999) as follows: NFC $(\mathrm{g} / \mathrm{kg}$ of DM $)=100-(\mathrm{NDF}+$ $\mathrm{CP}+$ ash + ether extract).

\section{Statistical Analysis}

Data on glucose and insulin concentration, glucose k, and glucose T1/2 were analyzed using PROC MIXED of SAS (version 9.0, SAS Institute Inc., Cary, NC) accounting for repeated measurements. The model included the fixed effect of the diets in the intrauterine phase (2 levels: fiber and starch), the fixed effect of diets in the growth phase (2 levels: fiber and starch), the effect of time, and their interactions and the random effect of animal. Data on QUICKI, HOMA, $\mathrm{AUC}_{\text {glucose }}$, $\mathrm{AUC}_{\text {insulin, }}$ insulin peak, and insulin increment were analyzed using PROC GLM of SAS (version 9.0, SAS Institute Inc.). The model included the fixed effect of the diets in the intrauterine phase (2 levels: fiber and starch), the fixed effect of diets in the growth phase (2 
Table 2. Mean baseline plasma glucose and insulin concentrations 15 min before and 180 min after the intravenous infusion of a glucose (dextrose) solution at $0.5 \mathrm{~g} / \mathrm{kg}$ of BW in 20 nulliparous ewes pregnant with a single fetus (d $124 \pm 2$ of gestation)

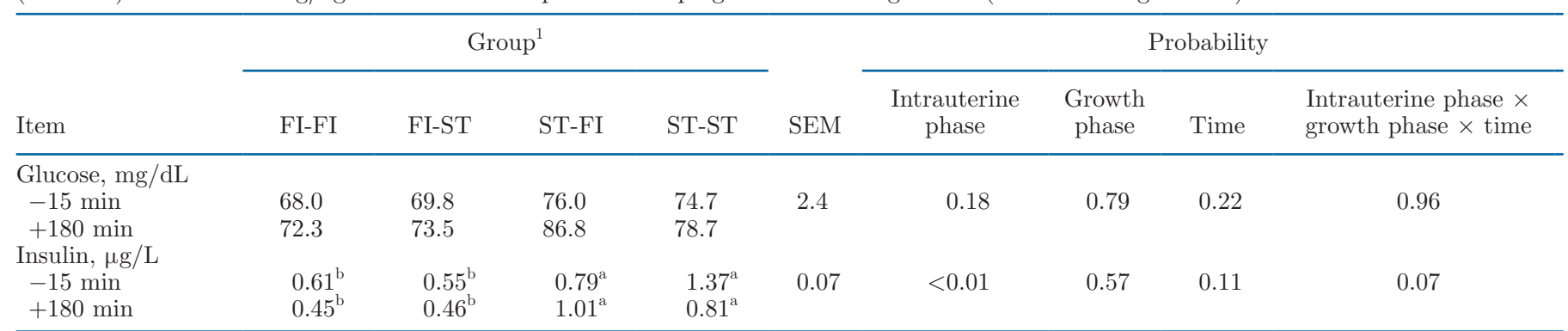

${ }^{\mathrm{a}, \mathrm{b}}$ Means within a row with different superscripts are statistically different $(P<0.05)$.

${ }^{1}$ Ewes were exposed to diets based on different dietary carbohydrates (fiber, FI, or starch, ST) during the last $75 \mathrm{~d}$ of their intrauterine life and from $15 \mathrm{~d}$ after birth to their first gestation (growth period), resulting in 4 dietary regimens $(\mathrm{n}=5$ per dietary regimen): FI-FI $=$ FI diet during both intrauterine and growth life; FI-ST = FI diet in intrauterine life followed by the ST diet in the growth phase; ST-FI = ST diet in intrauterine life followed by the FI diet in the growth phase; ST-ST = ST diet during both intrauterine and growth life.

levels: fiber and starch), and their interactions. All data were expressed as mean \pm standard error of the mean. Means were separated using Tukey's test. The accepted level of significance was $P<0.05$.

\section{RESULTS}

Baseline glucose concentrations $(-15 \mathrm{~min}$ and +180 min after IVGTT) in pregnant offspring at d $124 \pm$ 2 of gestation were not affected by the carbohydrates (starch vs. fiber) offered during the last $75 \mathrm{~d}$ of their intrauterine life and from weaning to their first gestation (Table 2). On the contrary, baseline insulin concentration $(-15 \mathrm{~min}$ and $+180 \mathrm{~min})$ were higher $(P<0.01$; Table 2) in pregnant offspring whose mothers received the ST diet $(0.97 \mu \mathrm{g} / \mathrm{L})$ than in those fed the FI diet $(0.52 \mu \mathrm{g} / \mathrm{L})$ during the last $75 \mathrm{~d}$ of their gestation (intrauterine phase). Feeding regimens of the growth phase did not affect basal insulin (Table 2).

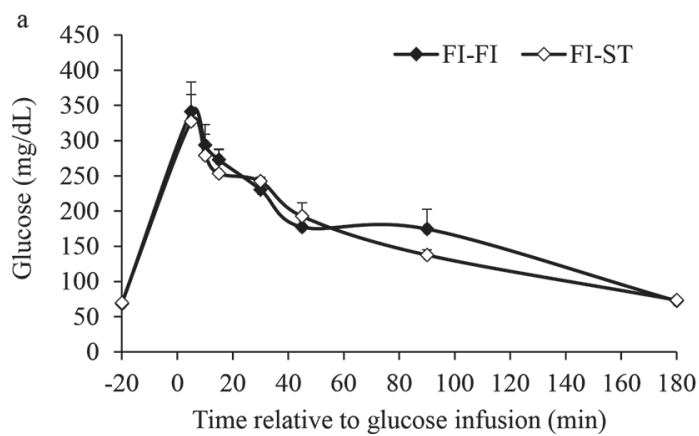

Following glucose infusion (from +5 to $+90 \mathrm{~min}$ ), glucose (Figure 2a and b) and insulin (Figure 3a and b) concentrations increased but were not affected by the diets offered in the intrauterine and growth phases $(P>0.05)$. The pattern of glucose and insulin concentration during the IVGTT was different. Plasma glucose concentrations $(\mathrm{mg} / \mathrm{dL})$ reached the peak $(\mathrm{ST}$ FI: $383.5 \pm 7.23$; FI-FI: $341.0 \pm 24.5$; FI-ST: $327.0 \pm$ 56.3; ST-ST: $305.3 \pm 68.6) 5 \mathrm{~min}$ after the infusion and decreased until +180 min, when they returned to the blood baseline concentrations (Figure 2a and b; effect of time $P<0.0001)$. Insulin concentrations $(\mu \mathrm{g} / \mathrm{L})$ reached the peak earlier $(P<0.001)$ in FI-FI and STFI offspring (1.80 \pm 0.40 and $2.22 \pm 0.62$, respectively; 10 min postinfusion) compared with FI-ST and ST-ST offspring $(2.17 \pm 0.90$ and $3.10 \pm 0.83$, respectively; 15 and 30 min postinfusion; Figure $3 \mathrm{a}$ and b).

The marker of insulin resistance, HOMA, was affected $(P=0.046)$ by the intrauterine $\times$ growth phases inter-

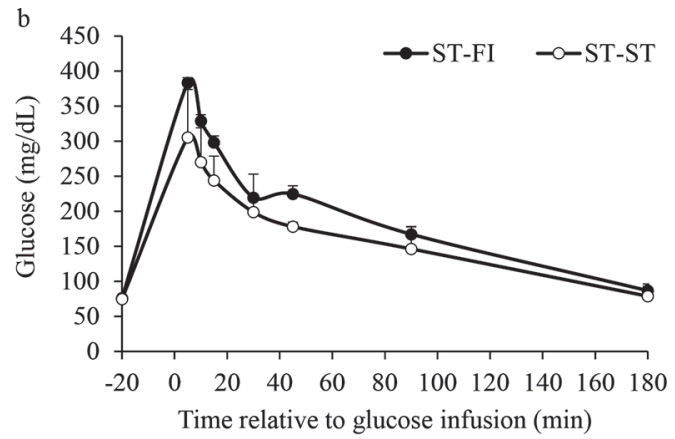

Figure 2. Mean plasma glucose concentrations in response to the intravenous infusion of a glucose (dextrose) solution at $0.5 \mathrm{~g} / \mathrm{kg}$ of $\mathrm{BW}$ in 20 nulliparous ewes pregnant with a single fetus (d $124 \pm 2$ of gestation). Ewes were exposed to diets based on different prevalent dietary carbohydrates (fiber, FI, or starch, ST) during the last $75 \mathrm{~d}$ of their intrauterine life and from $15 \mathrm{~d}$ after birth to their first gestation (growth period), resulting in 4 dietary regimens until the intravenous glucose tolerance test ( $\mathrm{n}=5$ per group): FI-FI $=$ FI diet during both intrauterine and growth life; FI-ST = FI diet in intrauterine life followed by the ST diet in the growth phase; ST-FI = ST diet in intrauterine life followed by the FI diet in the growth phase; ST-ST $=$ ST diet during both intrauterine and growth life. Glucose concentrations varied with time $(P<$ 0.0001 ) but were not influence by dietary carbohydrates during intrauterine or growth life. Error bars indicate SEM. 

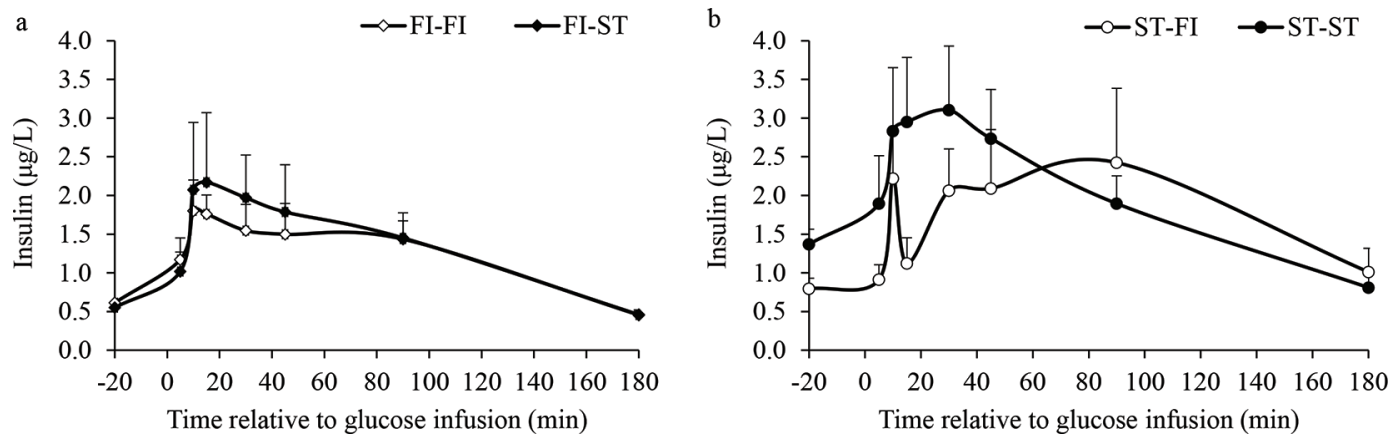

Figure 3. Plasma insulin concentration in response to the intravenous infusion of a glucose (dextrose) solution at $0.5 \mathrm{~g} / \mathrm{kg}$ of BW in $20 \mathrm{nul}-$ liparous ewes pregnant with a single fetus (d $124 \pm 2$ of gestation). Ewes were exposed to diets based on different prevalent dietary carbohydrates (fiber, FI, or starch, ST) during the last $75 \mathrm{~d}$ of their intrauterine life and from $15 \mathrm{~d}$ after birth to their first gestation (growth period), resulting in 4 dietary regimens until the intravenous glucose tolerance test $(\mathrm{n}=5$ per group): FI-FI $=$ FI diet during both intrauterine and growth life; FI-ST = FI diet in intrauterine life followed by the ST diet in the growth phase; ST-FI = ST diet in intrauterine life followed by the FI diet in the growth phase; ST-ST = ST diet during both intrauterine and growth life. The probability values for feeding strategies in the intrauterine life were $P<0.01$ at basal values and $P>0.05$ after glucose infusion. The effect of feeding strategies during the growth phase was $P>0.05$. The effect of time was $P<0.0001$. Error bars indicate SEM.

action; the offspring that received the ST diet in the intrauterine phase and fed the same diet in the growth phase (group ST-ST) exhibited higher values than the offspring receiving the FI diet in the intrauterine phase regardless of the growth diet (groups FI-FI and FI-ST; Table 3). The QUICKI, an index of insulin sensitivity, was significantly higher in the offspring fed FI (0.30) than in those fed ST (0.28) diets in the intrauterine phase $(P=0.0024$; Table 3$)$. The $\mathrm{AUC}_{\text {glucose }}, \mathrm{AUC}_{\text {insulin }}$, insulin peak, insulin increment (Table 3), glucose $\mathrm{k}$, and glucose T1/2 (Table 4) were not affected by the diets offered in the intrauterine and growth phases. Glucose $\mathrm{k}$ was affected by the effect of time $(P=0.048)$, which was higher at $+45 \mathrm{~min}(1.20 \% / \mathrm{min})$ than at $+90 \mathrm{~min}$ $(0.78 \% / \mathrm{min}$; Table 4$)$.

\section{DISCUSSION}

The most significant finding of the present study is that offspring exposed to a maternal starch-based diet offered during the last $75 \mathrm{~d}$ of gestation had increased insulin baseline concentrations and insulin resistance when measured postnatally during their first pregnancy. Specifically, the starch diet during intrauterine life increased basal insulin concentrations and HOMA in pregnant nulliparous offspring, whereas glucose concentrations, glucose tolerance (as assessed with the area under the curve), and insulin tolerance (as assessed with $\mathrm{AUC}_{\text {insulin }}$ ) were not affected. This is particularly relevant because fetal adipose tissue is believed to develop and differentiate during the last part

Table 3. Area under the curve for glucose $\left(\mathrm{AUC}_{\text {glucose}}\right)$, homeostasis model assessment (HOMA), quantitative insulin check index (QUICKI) and insulin response (peak insulin, insulin increment and area under the curve for insulin, $\mathrm{AUC}_{\text {insulin }}$ ) in 20 nulliparous ewes pregnant with a single fetus (d $124 \pm 2$ of gestation)

\begin{tabular}{|c|c|c|c|c|c|c|c|c|}
\hline Item & \multicolumn{4}{|c|}{ Group $^{1}$} & SEM & \multicolumn{3}{|c|}{ Probability } \\
\hline $\log \mathrm{AUC}_{\text {glucose }}, \mathrm{mg} / \mathrm{dL} \times \min$ & 29,079 & 27,124 & 31,203 & 25,628 & 992 & 0.70 & 0.11 & 0.50 \\
\hline HOMA & $4.79^{\mathrm{b}}$ & $4.39^{\mathrm{b}}$ & $6.82^{\mathrm{ab}}$ & $11.95^{\mathrm{a}}$ & 0.96 & $<0.01$ & 0.08 & $<0.05$ \\
\hline QUICKI & $0.30^{\mathrm{a}}$ & $0.30^{\mathrm{a}}$ & $0.28^{\mathrm{b}}$ & $0.27^{\mathrm{b}}$ & 0.004 & $<0.01$ & 0.68 & 0.11 \\
\hline Linear $\mathrm{AUC}_{\text {insulin }}, \mu \mathrm{g} / \mathrm{L} \times \min$ & 228.45 & 330.20 & 239.63 & 348.65 & 35.6 & 0.18 & 0.84 & 0.96 \\
\hline $\log \mathrm{AUC}_{\text {insulin }}, \mu \mathrm{g} / \mathrm{L} \times \min$ & 210.15 & 316.95 & 229.18 & 336.28 & 33.3 & 0.14 & 0.78 & 0.99 \\
\hline
\end{tabular}

\footnotetext{
${ }^{\mathrm{a}, \mathrm{b}}$ Means within a row with different superscripts differ $(P<0.05)$.
}

${ }^{1}$ Ewes were exposed to diets based on different dietary carbohydrates (fiber. FI, or starch. ST) during the last $75 \mathrm{~d}$ of their intrauterine life and from $15 \mathrm{~d}$ after birth to their first gestation (growth period), resulting in 4 dietary regimens $(\mathrm{n}=5$ per dietary regimen): FI-FI $=$ FI diet during both intrauterine and growth life; FI-ST = FI diet in intrauterine life followed by the ST diet in the growth phase; ST-FI = ST diet in intrauterine life followed by the FI diet in the growth phase; ST-ST = ST diet during both intrauterine and growth life. 
of gestation (Symonds and Stephenson, 1999; Symonds et al., 2009; Nielsen et al., 2016). In fact, Khanal and Nielsen (2017) observed that both prenatal overnutrition (150\% of energy and $110 \%$ of protein requirements) and undernutrition (50\% of energy and protein requirements) during late pregnancy led to changes in fat deposition patterns in adolescent offspring $(\sim 6$ mo of age). Undernourished lambs also showed an increased number of a subpopulation of very small adipocytes $(<40-\mu \mathrm{m}$ diameter) in subcutaneous fat (Khanal and Nielsen, 2017). The same authors also stated that late-gestation under- and overnutrition followed by exposure to a high-fat diet in early postnatal life are associated with markedly increased perirenal adipocyte hypertrophy. These changes were also associated with altered lipid accumulation in the liver and impaired glucose-insulin homeostasis (lower insulin sensitivity and increased compensatory levels of insulin secretion; Khanal and Nielsen, 2017). Evidence from the same sheep model suggested that early postnatal diets, but not late-gestation diets, affected long-term mechanisms of insulin action at muscle level; thus, observed effects should involve other tissues (Hou et al., 2013). A normal compensatory action of pancreas insulin secretion on glucose clearance with different late-gestation diets was observed, whereas alteration of pancreatic compensatory action on glucose regulation, lower glucose clearance, and pancreatic fibrosis was associated with high-fat diets offered in early postnatal life (Kongsted et al., 2014). However, pancreatic functions for complete insulin homeostasis are not clearly understood, whereas insulin resistance in ruminant species has been associated with impaired insulin binding to adipocytes (Baumgard et al., 2016) more than with depression of pancreatic functions (De Koster and Opsomer, 2013).

In the present study, following glucose infusion, blood glucose concentrations increased as expected, reaching their peak $5 \mathrm{~min}$ after the infusion. The highest glucose concentrations (ST-FI: $383.5 \mathrm{mg} / \mathrm{dL}$ ) were approximately $33 \%$ higher than those previously reported in singleton pregnancies of Sarda ewes (Morgante et al., 2012). The reason for this discrepancy is unclear. Fasting time before IVGTT was similar between the present study and that of Morgante et al. (2012), whereas it was not possible to compare BW and days of pregnancy between the 2 studies because they were not reported in that study. The only noticeable difference was the animal age: these authors carried out the IVGTT in sheep that were from 2 to $7 \mathrm{yr}$ old, whereas we challenged primiparous ewes. Thus, the difference in the response to the IVGTT between the previous study performed is Sarda sheep (Morgante et al., 2012) and the present one could be due to differences in both the age and stage of gestation of the ewes enrolled in the 2 trials.

Insulin release in the IVGTT showed a biphasic pattern, similar to what occurs in humans (Katz et al., 2000 ) and in accordance with what was previously observed by Morgante et al. (2012) in nonpregnant Sarda ewes challenged with IVGTT. As suggested by Caumo and Luzi (2004), the insulin response to glucose infusion usually shows a biphasic profile: acute in the first phase, decrease until $10 \mathrm{~min}$, and further increase until 30 min after glucose infusion. This is generally associated with a typical response to exposure of $\beta$-cells to a fast change in glucose concentrations, whereas it does not occur under physiological conditions in animals not exposed to external glucose infusion (Caumo and Luzi, 2004; Baumgard et al., 2016).

The highest basal insulin concentration observed in offspring fed the ST diet in the intrauterine phase can be considered an indicator of low insulin sensitivity (Hoffman et al., 2016). This indication is also confirmed by observed HOMA values (Table 3). Low insulin sensitivity affects glucose uptake from insulindependent peripheral tissues, such as adipocyte and muscle cells (Sasaki, 2002), and it is characterized by a

Table 4. Glucose fractional turnover rate $(\mathrm{k})$ and glucose half time $(\mathrm{T} 1 / 2)$ at +45 and +90 min after the intravenous infusion of a glucose (dextrose) solution at $0.5 \mathrm{~g} / \mathrm{kg}$ of BW in 20 nulliparous ewes pregnant with a single fetus (d $124 \pm 2$ of gestation)

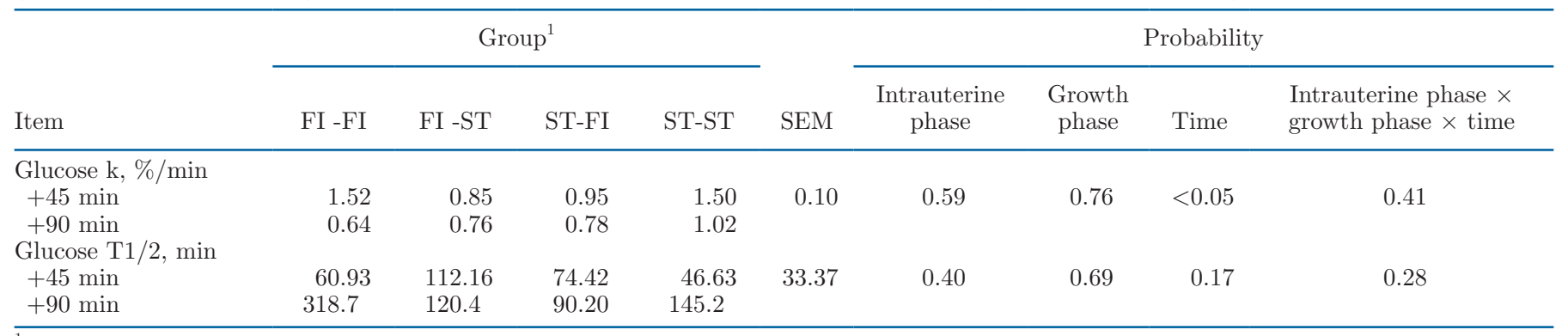

${ }^{1}$ Ewes were exposed to diets based on different dietary carbohydrates (fiber, FI, or starch, ST) during the last $75 \mathrm{~d}$ of their intrauterine life and from $15 \mathrm{~d}$ after birth to their first gestation (growth period), resulting in 4 dietary regimens $(\mathrm{n}=5$ per dietary regimen): FI-FI $=$ FI diet during both intrauterine and growth life; FI-ST = FI diet in intrauterine life followed by the ST diet in the growth phase; ST-FI = ST diet in intrauterine life followed by the FI diet in the growth phase; ST-ST = ST diet during both intrauterine and growth life. 
reduced response to insulin (Soeters and Soeters, 2012) at physiological insulin concentrations (De Koster and Opsomer, 2013). Also, low insulin sensitivity is usually reversible in ruminants; it is a temporary adaptation to a specific physiological stage, such as gestation, when blood glucose is directed toward the fetus or the mammary gland, where glucose uptake is mediated via insulin-independent pathways (Bell and Bauman, 1997; De Koster and Opsomer, 2013; De Koster et al., 2017).

Alterations of glucose metabolism have been identified as a negative consequence of maternal undernutrition. Sheep have much higher nutrient requirements during gestation compared with cattle and are consequently exposed to a greater risk of undernutrition in pregnancy (Cannas et al., 2016). Evidence of the effects of maternal under- and overnutrition on impaired glucose metabolism of lambs and ewes was demonstrated in previous studies. Indeed, sheep undernutrition during early and mid gestation reduced postnatal growth and glucose uptake and increased blood glucose and insulin secretion, inducing a consequential altered adiposity in male offspring (Ford et al., 2007). Severe maternal undernutrition [60\% of NRC (1992) requirements in the last $31 \mathrm{~d}$ of gestation] increased basal insulin concentration in their lambs (first 3 mo of age) compared with control lambs $(0.49$ vs. $0.12 \pm 0.12 ; P=0.01)$ during a glucose tolerance test in sheep (Hoffman et al., 2016). Thus, nutritional level and energy balance can be considered fundamental in programming glucose metabolism of the offspring. Similar effects were attributed to lipogenic and obesogenic diets (from fat sources) offered in the intrauterine phase or early in life (Kongsted et al., 2014; Khanal et al., 2015; Khanal and Nielsen, 2017). On the other hand, very scarce evidence is available in relation to dietary or carbohydrate effects. The present work provides evidence of the positive effect of glucogenic carbohydrates on the alteration of glucose metabolism in sheep. Alteration of glucose metabolism due to fetal exposure to challenging metabolic and environmental conditions has been related to development of low insulin sensitivity in adipose tissue of sheep (Khanal and Nielsen, 2017). We supposed that constant and high exposure to glucose in this fetal phase, a time of high susceptibility to metabolic programming changes, could have induced a permanent lowered response to glucose in the peripheral tissues. This could be related to the basic role, which is more important in sheep than in other dairy ruminants, of acetate derived from fiber fermentation as an energetic and precursor substrate (Pethick and Lindsay, 1982; Cannas et al., 2002). Pethick and Lindsay (1982) observed that (1) in sheep muscle the energy requirement is largely covered by acetate independently from the physiological stage; (2) homeostasis regulation results from the interaction of dietary nutrient intake and tissue metabolism of acetate; and (3) the glucose utilization rate by the udder with respect to the whole-body glucose utilization rate may be lower in sheep than in cows and goats, with acetate used as an energy source for the mammary gland and possibly sparing glucose to lactose production. Various experiments showed that adult sheep are very sensitive to insulin action when fed starchy diets in lactation, especially after the peak of lactation, and thus are prone to accumulate body reserves (a tissue with insulin receptors) and reduce milk production (mammary gland is insulin independent) in these feeding conditions (Cannas et al., 2002, 2013, 2016; Lunesu, 2016). Sheep are certainly more sensitive to this mechanism than specialized dairy goats (Lunesu, 2016) and likely dairy cows, possibly because sheep underwent a limited genetic selection for milk production compared with the other 2 dairy species (Cannas et al., 2002). In this sense, the lowered insulin sensitivity induced by the supply of a starchy diet in intrauterine life might favor their nutrient partitioning toward insulin-independent sites (fetus and mammary gland) during their productive life.

In this study, the lack of differences in glucose concentration, $\mathrm{AUC}_{\text {glucose }}$, and $\mathrm{AUC}_{\text {insulin }}$ among groups was not expected, especially for animals fed the ST diet in the intrauterine phase, which received higher dietary glucose precursors compared with the FI diet. It must be noted that the glucose concentration curves during IVGTT were very similar in all groups, whereas insulin patterns differed among groups. This suggests that in these animals a pancreatic secretion response occurred during the IVGTT to modulate the blood glucose concentration. Consequentially, the insulin response occurred under different stimuli among groups, and hyperinsulinemic patterns were observed for ewes fed the ST diet in the intrauterine phase. This probably indicates an attempt to compensate for the tissue sensitivity heightened by the physiological priority of maintaining constant glucose homeostasis for the gravid uterus (Husted et al., 2008). This conclusion is in line with the findings of Kongsted et al. (2014) and Khanal et al. (2015), who observed compensatory upregulation of insulin secretion in animals with decreased peripheral insulin sensitivity due to maternal undernutrition (Khanal and Nielsen, 2017).

In this physiological stage, it is difficult to discriminate glucose uptake from insulin-independent rather than insulin-dependent organs, as previously observed in pregnant ewes (Morgante et al., 2012; Duehlmeier et al., 2013). Thus, data derived from the IVGTT should be considered and interpreted differently in relation to the physiological stages of the animals (De Koster et al., 2017). To the best of our knowledge, no other stud- 
ies have compared the effect of exposure to different dietary carbohydrates in intrauterine life on glucose and insulin metabolism in the adult progeny using diets that fully covered their energy requirements. Only one study on pregnant mares evaluated the effect of high-starch diets on glucose and insulin metabolism in their offspring at 5, 40, 80, and $160 \mathrm{~d}$ of age (George et al., 2009). The authors observed the highest basal glucose and insulin concentrations in the foals of mares receiving high-starch diets during their pregnancy, as observed in this study for basal insulin. It appears, then, that starch-rich diets fed during the intrauterine phase produce a sort of permanent low insulin sensitivity in addition to that induced by the physiological state of gestation.

We assessed a low insulin sensitivity in pregnant adult offspring born to dams fed a starch diet. The use of starchy diets during the intrauterine phase was still effective in adulthood. The use of starchy diets during intrauterine life could probably represent a way to favor nutrient partitioning toward insulin-independent sites (fetus and mammary gland). If more nutrients are partitioned toward the gravid uterus, greater development of the placenta could be expected, with possible positive effects also on the production of the placental lactogen hormone, which increases mammary epithelium and consequently favors milk production. Other positive effects might be expected, such as higher offspring weight or lower lamb mortality rate. Conversely, considering the broad literature on the negative effects of insulin resistance on the development of metabolic disorders in humans (Kahn et al., 2006; Cottrell and Ozanne, 2008) and ruminants (Ji et al., 2012), the voluntary induction of low insulin sensitivity should be carefully investigated and tested for its long-term effects and possible interactions with physiological status and body reserves. Potential risks have to be considered, especially in overfed and overconditioned animals (De Koster et al., 2015). It also might be useful to test whether lower insulin sensitivity, induced by metabolic programming, might allow the ewe to maintain the priority of nutrient partitioning to the mammary gland during lactation to extend its persistency, because altered insulin sensitivity favors energy partitioning to the udder in lactation (De Koster and Opsomer, 2013; Baumgard et al., 2017). Indeed, diets rich in highly digestible fiber sources fed to ewes in mid lactation improved dairy sheep lactation persistency compared with starchy diets, probably because they reduced the stimulation of insulin action in a species very sensitive to it, thus favoring the mammary gland (Cannas et al., 2013; Lunesu, 2016; Lunesu et al., 2017). Should these speculations be supported by evidence, the diets offered in late gestation may be used to program glucose metabolism in the progeny, thus improving nutrient partitioning and milk yield in dairy ewes. This would fit in animal husbandry the goal of using fetal programming to improve production (Kenyon and Blair, 2014) and to prevent adverse outcomes for animal health during the most critical physiological stages (Cottrell and Ozanne, 2008; Khanal and Nielsen, 2017).

\section{CONCLUSIONS}

This research explored the response to a glucose tolerance test carried out on pregnant nulliparous ewes differing in the prevalent type of carbohydrates (starch vs. highly digestible fiber) fed during the last $75 \mathrm{~d}$ of their intrauterine life (i.e., fed to their mothers during the last $75 \mathrm{~d}$ of pregnancy) and during their postnatal life until their first pregnancy. The diet rich in starch offered during the intrauterine life increased basal insulin concentrations and induced a low insulin sensitivity status during the subsequent first pregnancy, whereas no effects were observed as a result of the feeding treatments applied during the postnatal life. This is evidence of dietary effects on fetal programming. Thus, the use of starchy diets in the mothers during the intrauterine life of their offspring may be used to modulate insulin sensitivity of the adipose tissue and conveniently implement fetal programming strategies of dairy ewes (e.g., to partition more nutrients toward the fetus or the mammary gland). However, additional studies are required to confirm these observations, to evaluate the optimal maternal nutritional plans to enhance metabolic and productive performances of their offspring, and to avoid negative effects on metabolic regulations.

\section{ACKNOWLEDGMENTS}

This research was supported by the project "Permanent effects of starch and fiber, supplied during uterine and postnatal life of dairy sheep, on gastrointestinal microbiota and energy partitioning between milk production and fat deposition," funded by the Italian Ministry of University and Research (Rome, Italy) in the Program "Futuro in Ricerca," FIR, 2013 (LI 1-cod. RBFR13V9JE). The authors declare that no conflicts of interest exist for this work.

\section{REFERENCES}

Accorsi, P. A., N. Govoni, R. Gaiani, C. Pezzi, E. Seren, and C. Tamanini. 2005. Leptin, GH, PRL, insulin and metabolic parameters throughout the dry period and lactation in dairy cows. Reprod. Domest. Anim. 40:217-223. https://doi.org/10.1111/j.1439-0531 .2005.00581.x.

AOAC International. 2000. Official Method of Analysis. 17th ed. AOAC International, Arlington, VA. 
AOAC International. 2005. Official Method of Analysis. 18th ed. AOAC International, Gaithersburg, MD.

Aschenbach, J. R., N. B. Kristensen, S. S. Donkin, H. M. Hammon, and G. B. Penner. 2010. Gluconeogenesis in dairy cows: The secret of making sweet milk from sour dough. IUBMB Life 62:869-877. https://doi.org/10.1002/iub.400.

Barker, D. J. 2007. The origins of the developmental origins theory. J. Intern. Med. 261:412-417. https://doi.org/10.1111/j.1365-2796 2007.01809.x.

Bauman, D. E., and W. B. Currie. 1980. Partitioning of nutrients during pregnancy and lactation: A review of mechanisms involving homeostasis and homeorhesis. J. Dairy Sci. 63:1514-1529. https:// doi.org/10.3168/jds.S0022-0302(80)83111-0.

Baumgard, L. H., R. J. Collier, and D. E. Bauman. 2017. A 100-year review: Regulation of nutrient partitioning to support lactation. J. Dairy Sci. 100:10353-10366. https://doi.org/10.3168/jds.2017 $-13242$.

Baumgard, L. H., G. J. Hausman, and M. V. Sanz Fernandez. 2016. Insulin: Pancreatic secretion and adipocyte regulation. Domest. Anim. Endocrinol. 54:76-84. https://doi.org/10.1016/j.domaniend 2015.07.001

Bell, A. W., and D. E. Bauman. 1997. Adaptations of glucose metabolism during pregnancy and lactation. J. Mammary Gland Biol. Neoplasia 2:265-278. https://doi.org/10.1023/A:1026336505343.

Bovera, F., M. I. Cutrignelli, S. Calabrò, G. Piccolo, R. Tudisco, F. Zicarelli, V. Piccolo, and F. Infascelli. 2004. Effects of non-structural carbohydrate dietary content on the productive performance of Sarda primiparous ewes. Ital. J. Anim. Sci. 3:61-70. https://doi .org/10.4081/ijas.2004.61.

Cannas, A., A. Cabiddu, G. C. Bomboi, S. Ligios, B. Floris, and G. Molle. 2013. Decreasing dietary NFC concentration during midlactation of dairy ewes: Does it result in higher milk production? Small Rumin. Res. 111:41-49. https://doi.org/10.1016/j .smallrumres.2012.09.009.

Cannas, A., A. Nudda, and G. Pulina. 2002. Nutritional strategies to improve lactation persistency in dairy ewes. Pages 17-59 in Proc. of the 8th Great Lakes Dairy Sheep Symposium, Cornell University, Ithaca, NY. Spooner Agricultural Research Station Publications, Spooner, WI.

Cannas, A., M. L. Thonney, and M. F. Lunesu. 2016. Feeding dairy sheep: Nutritional challenges and opportunities. Pages 69-80 in Dairy Sheep Assoc. of North Am. Symp., Ithaca, NY. Cornell University, Ithaca, NY.

Caumo, A., and L. Luzi. 2004. First-phase insulin secretion: Does it exist in real life? Considerations on shape and function. Am. J. Physiol. Endocrinol. Metab. 287:E371-E385. https://doi.org/10 .1152 /ajpendo.00139.2003.

Cottrell, E. C., and S. E. Ozanne. 2008. Early life programming of obesity and metabolic disease. Physiol. Behav. 94:17-28. https:// doi.org/10.1016/j.physbeh.2007.11.017.

Coverdale, J. A., C. J. Hammer, and K. W. Walter. 2015. Horse Species Symposium: Nutritional programming and the impact on mare and foal performance. J. Anim. Sci. 93:3261-3267. https:// doi.org/10.2527/jas.2015-9057.

De Koster, J., M. Hostens, M. Van Eetvelde, K. Hermans, S. Moerman, H. Bogaert, E. Depreester, W. Van Den Broeck, and G. Opsomer. 2015. Insulin response of the glucose and fatty acid metabolism in dry dairy cows across a range of body condition scores. J. Dairy Sci. 98:4580-4592. https://doi.org/10.3168/jds.2015-9341.

De Koster, J., M. Van Eetvelde, K. Hermans, W. Van Den Broeck, M. Hostens, and G. Opsomer. 2017. Limitations of glucose tolerance tests in the assessment of peripheral tissue insulin sensitivity during pregnancy and lactation in dairy heifers. J. Dairy Sci. 100:2381-2387. https://doi.org/10.3168/jds.2016-11792.

De Koster, J. D., and G. Opsomer. 2013. Insulin resistance in dairy cows. Vet. Clin. North Am. Food Anim. Pract. 29:299-322. https: //doi.org/10.1016/j.cvfa.2013.04.002.

Duehlmeier, R., I. Fluegge, B. Schwert, and M. Ganter. 2013. Insulin sensitivity during late gestation in ewes affected by pregnancy toxemia and in ewes with high and low susceptibility to this dis- order. J. Vet. Intern. Med. 27:359-366. https://doi.org/10.1111/ jvim. 12035 .

European Commission. 1999. Commission directive of 27 July 1999 amending the third Commission Directive 72/199/EEC of 27 April 1972 establishing Community methods of analysis for the official control of feeding stuffs (text with EEA relevance). Off. J. L209: $23-27$.

European Parliament. 2010. Directive 2010/63/EU of the European Parliament and of the Council of 22 September 2010 on the protection of animals used for scientific purposes. Off. J. Eur. Union L 276:33-79.

Ford, S. P., B. W. Hess, M. M. Schwope, M. J. Nijland, J. S. Gilbert, K. A. Vonnahme, V. J. Means, H. Han, and P. W. Nathanielsz. 2007. Maternal undernutrition during early to mid-gestation in the ewe results in altered growth, adiposity, and glucose tolerance in male offspring. J. Anim. Sci. 85:1285-1294. https://doi.org/10 $.2527 /$ jas.2005-624.

George, L. A., W. B. Staniar, K. H. Treiber, P. A. Harris, and R. J. Geor. 2009. Insulin sensitivity and glucose dynamics during preweaning foal development and in response to maternal diet composition. Domest. Anim. Endocrinol. 37:23-29. https://doi.org/10 .1016/j.domaniend.2009.01.003.

Hoffman, M. L., K. N. Peck, M. E. Forella, A. R. Fox, K. E. Govoni, and S. A. Zinn. 2016. The effects of poor maternal nutrition during gestation on postnatal growth and development of lambs. J. Anim. Sci. 94:789-799. https://doi.org/10.2527/jas.2015-9933.

Hou, L., A. H. Kongsted, S. M. Ghoreishi, T. K. Takhtsabzy, M. Friedrichsen, L. I. Hellgren, H. N. Kadarmideen, A. Vaag, and M. O. Nielsen. 2013. Pre- and early-postnatal nutrition modify gene and protein expressions of muscle energy metabolism markers and phospholipid fatty acid composition in a muscle type specific manner in sheep. PLoS One 8:e65452. https://doi.org/10.1371/journal .pone.0065452.

Husted, S. M., M. O. Nielsen, D. Blache, and K. L. Ingvartsen. 2008. Glucose homeostasis and metabolic adaptation in the pregnant and lactating sheep are affected by the level of nutrition previously provided during her late fetal life. Domest. Anim. Endocrinol. 34:419-431. https://doi.org/10.1016/j.domaniend.2007.12.002.

Ipharraguerre, I. R., R. R. Ipharraguerre, and J. H. Clark. 2002. Performance of lactating dairy cows fed varying amounts of soyhulls as a replacement for corn grain. J. Dairy Sci. 85:2905-2912. https: //doi.org/10.3168/jds.S0022-0302(02)74378-6.

Ji, P., J. S. Osorio, J. K. Drackley, and J. J. Loor. 2012. Overfeeding a moderate energy diet prepartum does not impair bovine subcutaneous adipose tissue insulin signal transduction and induces marked changes in peripartal gene network expression. J. Dairy Sci. 95:4333-4351. https://doi.org/10.3168/jds.2011-5079.

Kahn, C. R. 1978. Insulin resistance, insulin sensitivity, and insulin responsiveness: A necessary distinction. Metabolism 27:1893-1902. https://doi.org/10.1016/S0026-0495(78)80007-9.

Kahn, S. E., R. L. Hull, and K. M. Utzschneider. 2006. Mechanisms linking obesity to insulin resistance and type 2 diabetes. Nature 444:840-846. https://doi.org/10.1038/nature05482.

Katz, A., S. S. Nambi, K. Mather, A. D. Baron, D. A. Follmann, G. Sullivan, and M. J. Quon. 2000. Quantitative insulin sensitivity check index: A simple, accurate method for assessing insulin sensitivity in humans. J. Clin. Endocrinol. Metab. 85:2402-2410. https: //doi.org/10.1210/jcem.85.7.6661.

Kenyon, P. R., and H. T. Blair. 2014. Foetal programming in sheepEffects on production. Small Rumin. Res. 118:16-30. https://doi .org/10.1016/j.smallrumres.2013.12.021.

Khanal, P., A. Axel, A. Kongsted, S. V. Husted, L. Johnsen, D. Pandey, K. L. Pedersen, M. Birtwistle, B. Markussen, H. N. Kadarmideen, and M. O. Nielsen. 2015. Late gestation under-and overnutrition have differential impacts when combined with a post-natal obesogenic diet on glucose-lactate-insulin adaptations during metabolic challenges in adolescent sheep. Acta Physiol. (Oxf.) 213:519-536. https://doi.org/10.1111/apha.12391.

Khanal, P., and M. O. Nielsen. 2017. Impacts of prenatal nutrition on animal production and performance: A focus on growth and meta- 
bolic and endocrine function in sheep. J. Anim. Sci. Biotechnol. 8:75. https://doi.org/10.1186/s40104-017-0205-1.

Kongsted, A. H., M. P. Tygesen, S. V. Husted, M. H. Oliver, A. Tolver, V. G. Christensen, J. H. Nielsen, and M. O. Nielsen. 2014. Programming of glucose-insulin homoeostasis: Long-term consequences of pre-natal versus early post-natal nutrition insults. Evidence from a sheep model. Acta Physiol. (Oxf.) 210:84-98. https://doi .org/10.1111/apha.12080.

Long, N. M., L. A. George, A. B. Uthlaut, D. T. Smith, M. J. Nijland, P. W. Nathanielsz, and S. P. Ford. 2010. Maternal obesity and increased nutrient intake before and during gestation in the ewe results in altered growth, adiposity, and glucose tolerance in adult offspring. J. Anim. Sci. 88:3546-3553. https://doi.org/10.2527/jas .2010-3083.

Lunesu, M. F. 2016. Modulation of dietary energy partitioning between milk production and body reserved in sheep and goats. $\mathrm{PhD}$ Thesis. University of Sassari, Sassari, Italy.

Lunesu, M. F., M. Decandia, G. Molle, M. Acciaro, G. Epifani, A. H. Dias Francesconi, A. S. Atzori, G. C. Bomboi, P. S. Nicolussi, A. Prandi, and A. Cannas. 2017. Effects of partially replacing cereal grains with soyhulls on energy partitioning in ewes and goats in mid lactation. Page 136 in Proc. Animal Science and Production Association (ASPA) 22nd Congress, Perugia, Italy. Taylor \& Francis, Abingdon, UK.

Matthews, D. R., J. P. Hosker, A. S. Rudenski, B. A. Naylor, D. F Treacher, and R. C. Turner. 1985. Homeostasis model assessment: Insulin resistance and $\beta$-cell function from fasting plasma glucose and insulin concentrations in man. Diabetologia 28:412-419. https: //doi.org/10.1007/BF00280883.

McFadden, J. W., and J. E. Rico. 2019. Invited review: Sphingolipid biology in the dairy cow: The emerging role of ceramide. J. Dairy Sci. 102:7619-7639. https://doi.org/10.3168/jds.2018-16095.

Morgante, M., M. Gianesella, S. Casella, C. Stelletta, C. Cannizzo, E. Giudice, and G. Piccione. 2012. Response to glucose infusion in pregnant and nonpregnant ewes: Changes in plasma glucose and insulin concentrations. Comp. Clin. Pathol. 21:961-965. https:// doi.org/10.1007/s00580-011-1208-5.

Mossa, F., D. Bebbere, A. Ledda, G. P. Burrai, I. Chebli, E. Antuofermo, S. Ledda, A. Cannas, F. Fancello, and A. S. Atzori. 2018. Testicular development in male lambs prenatally exposed to a high-starch diet. Mol. Reprod. Dev. 85:406-416. https://doi.org/ $10.1002 / \operatorname{mrd} .22974$

Nielsen, M. O., L. Hou, L. Johnsen, P. Khanal, C. L. Bechshøft, A. H. Kongsted, A. Vaag, and L. I. Hellgren. 2016. Do very small adipocytes in subcutaneous adipose tissue (a proposed risk factor for insulin insensitivity) have a fetal origin? Clin. Nutr. Exp. 8:9-24. https://doi.org/10.1016/j.yclnex.2016.05.003.

NRC. 1992. Nutrient Requirements of Sheep. Natl. Acad. Press, Washington, DC.

Paliy, O., C. J. Piyathilake, A. Kozyrskyj, G. Celep, F. Marotta, and R. Rastmanesh. 2014. Excess body weight during pregnancy and offspring obesity: Potential mechanisms. Nutrition 30:245-251. https://doi.org/10.1016/j.nut.2013.05.011.

Parlee, S. D., and O. A. MacDougald. 2014. Maternal nutrition and risk of obesity in offspring: The Trojan horse of developmental plasticity. Biochim. Biophys. Acta 1842:495-506. https://doi.org/ 10.1016/j.bbadis.2013.07.007.

Peel, C. J., and D. E. Bauman. 1987. Somatotropin and lactation. J. Dairy Sci. 70:474-486. https://doi.org/10.3168/jds.S0022 -0302(87)80030-9.

Pethick, D. W., and D. B. Lindsay. 1982. Acetate metabolism in lactating sheep. Br. J. Nutr. 48:319-328. https://doi.org/10.1079/ BJN19820116.
Pulina, G., A. Nudda, N. P. P. Macciotta, G. Battacone, S. P. G. Rassu, and A. Cannas. 2007. Non-nutritional factors affecting lactation persistency in dairy ewes: A review. Ital. J. Anim. Sci. 6:115-141. https://doi.org/10.4081/ijas.2007.115.

Ravelli, A. C., J. H. van der Meulen, R. P. J. Michels, C. Osmond, D. J. Barker, C. N. Hales, and O. P. Bleker. 1998. Glucose tolerance in adults after prenatal exposure to famine. Lancet 351:173-177. https://doi.org/10.1016/S0140-6736(97)07244-9.

Sasaki, S. I. 2002. Mechanism of insulin action on glucose metabolism in ruminants. Anim. Sci. J. 73:423-433. https://doi.org/10.1046/j .1344-3941.2002.00059.x.

Soeters, M. R., and P. B. Soeters. 2012. The evolutionary benefit of insulin resistance. Clin. Nutr. 31:1002-1007. https://doi.org/10 .1016/j.clnu.2012.05.011.

Symonds, M. E., S. P. Sebert, M. A. Hyatt, and H. Budge. 2009. Nutritional programming of the metabolic syndrome. Nat. Rev. Endocrinol. 5:604-610. https://doi.org/10.1038/nrendo.2009.195.

Symonds, M. E., and T. Stephenson. 1999. Maternal nutrition and endocrine programming of fetal adipose tissue development. Biochem. Soc. Trans. 27:97-103. https://doi.org/10.1042/bst0270097.

Tedeschi, L. O., A. Cannas, and D. G. Fox. 2010. A nutrition mathematical model to account for dietary supply and requirements of energy and other nutrients for domesticated small ruminants: The development and evaluation of the Small Ruminant Nutrition System. Small Rumin. Res. 89:174-184. https://doi.org/10.1016/j .smallrumres.2009.12.041.

Todd, S. E., M. H. Oliver, A. L. Jaquiery, F. H. Bloomfield, and J. E. Harding. 2009. Periconceptional undernutrition of ewes impairs glucose tolerance in their adult offspring. Pediatr. Res. 65:409-413. https://doi.org/10.1203/PDR.0b013e3181975efa.

van Knegsel, A. T. M., H. van den Brand, J. Dijkstra, W. M. van Straalen, R. Jorritsma, S. Tamminga, and B. Kemp. 2007. Effect of glucogenic vs. lipogenic diets on energy balance, blood metabolites, and reproduction in primiparous and multiparous dairy cows in early lactation. J. Dairy Sci. 90:3397-3409. https://doi.org/10 .3168/jds.2006-837.

Van Soest, P. J., J. B. Robertson, and B. A. Lewis. 1991. Methods for dietary fiber, neutral detergent fiber, and nonstarch polysaccharides in relation to animal nutrition. J. Dairy Sci. 74:3583-3597. https://doi.org/10.3168/jds.S0022-0302(91)78551-2.

Weiss, W. P. 1999. Energy prediction equations for ruminant feeds. Pages 176-185 in Proc. 61th Cornell Nutrition Conference for Feed Manufacturers, Ithaca, NY. Cornell University, Ithaca, NY.

Zachut, M., H. Honig, S. Striem, Y. Zick, S. Boura-Halfon, and U. Moallem. 2013. Periparturient dairy cows do not exhibit hepatic insulin resistance, yet adipose-specific insulin resistance occurs in cows prone to high weight loss. J. Dairy Sci. 96:5656-5669. https: //doi.org/10.3168/jds.2012-6142.

\section{ORCIDS}

M. F. Lunesu (® https://orcid.org/0000-0002-4260-6364

F. Correddu ๑ https://orcid.org/0000-0002-6098-7519

F. Fancello @ https://orcid.org/0000-0002-0023-7492

F. Mossa (๑ https://orcid.org/0000-0001-5517-1307

A. Nudda (๑) https://orcid.org/0000-0002-9807-0626

A. S. Atzori ৫ https://orcid.org/0000-0001-5083-241X 